\title{
Kendall B. Tarte, Writing Places. Sixteenth-Century City Culture and the Des Roches Salon
}

\section{Michele Mastroianni}

\section{Q OpenEdition \\ 1 Journals}

\section{Edizione digitale}

URL: http://journals.openedition.org/studifrancesi/7877

DOI: 10.4000/studifrancesi.7877

ISSN: 2421-5856

\section{Editore}

Rosenberg \& Sellier

\section{Edizione cartacea}

Data di pubblicazione: 1 juillet 2009

Paginazione: 381

ISSN: 0039-2944

\section{Notizia bibliografica digitale}

Michele Mastroianni, «Kendall B. Tarte, Writing Places. Sixteenth-Century City Culture and the Des Roches Salon», Studi Francesi [Online], 158 (LIII | II) | 2009, online dal 30 novembre 2015, consultato il 10 janvier 2021. URL: http://journals.openedition.org/studifrancesi/7877 ; DOI: https://doi.org/10.4000/ studifrancesi.7877

Questo documento è stato generato automaticamente il 10 janvier 2021.

\section{(c)}

Studi Francesi è distribuita con Licenza Creative Commons Attribuzione - Non commerciale - Non opere derivate 4.0 Internazionale. 


\title{
Kendall B. Tarte, Writing Places. Sixteenth-Century City Culture and the Des Roches Salon
}

\author{
Michele Mastroianni
}

\section{NOTIZIA}

KENDALL B. TARTE, Writing Places. Sixteenth-Century City Culture and the Des Roches Salon, Newark, University of Delaware Press, 2007, pp. 269.

1 Il volume di K.B. Tarte offre un quadro della produzione letteraria e culturale di un capoluogo di provincia, Poitiers, tra gli anni sessanta e ottanta del Cinquecento, in un periodo in cui la città fu centro importante, subendo un assedio da parte dei Protestanti, ospitando la corte di giustizia, accogliendo per una breve sessione (i Grands Jours de Poitiers) i giuristi parigini e dando vita con degli scrittori locali a uno dei primi salons umanisti. Viene ricostruita la vita intellettuale della città proprio a partire dal salon di Madeleine e Catherine Des Roches (madre e figlia) a cui nel periodo in questione facevano capo le personalità più rappresentative della cultura e della politica, sia cittadini di Poitiers sia ospiti di passaggio. I primi due capitoli ricostruiscono il contesto culturale del salon delle due Des Roches nel periodo in cui, nel 1579, ospita, fra gli altri i giuristi dei Grands Jours. È il momento in cui viene composta un'antologia poetica, La Puce de Madame des-Roches, una raccolta che, prendendo spunto da un gioco erotico che avrà fortuna barocca (quello della pulce, appunto, su petto di bella donna), mette in evidenza le interazioni culturali dei partecipanti al salon. L'A. ricostruisce, a partire dall'antologia in questione, sia il gruppo sociale del salon sia le tradizioni culturali contemporanee che si intersecano nei testi della raccolta: il blason, la descrizione topografica, le procedure legali. I due capitoli che seguono (3 e 4) completano lo studio specifico della comunità riunita intorno alle due Des Roches spostando l'attenzione sulla città di Poitiers, quale appare attraverso testi descrittivi e letterari che si collegano al gruppo del salon o servono a comprenderne il tessuto costitutivo. Tra 
questi testi un'attenzione particolare è rivolta a quelli incentrati sull'assedio della città ad opera dei Protestanti, nel 1569. Gli ultimi due capitoli (5 e 6) concentrano l'indagine su Madeleine e Catherine Des Roches, che vengono situate nel contesto delle donne scrittrici del Cinquecento. Mentre il capitolo 5 considera il ruolo sostenuto dalle donne nei conflitti religiosi degli anni sessanta e settanta del secolo, il capitolo 6 insiste ancora sull'idea di comunità intellettuale, ed è in funzione di questa comunità che le due Des Roches vengono studiate, attraverso la loro opera. 